\title{
THE INJURY METABOLISM OF THE CECROPIA SILKWORM-II. INJURY-INDUCED ALTERATIONS IN OXIDATIVE ENZYME SYSTEMS AND RESPIRATORY METABOLISM OF THE PUPAL WING EPIDERMIS*
}

\author{
DAVID G. SHAPPIRIO and WILLIAM R. HARVEY
}
Department of Zoology, The University of Michigan, Ann Arbor, and Department of Zoology, University of Massachusetts, Amherst

(Received 15 August 1964)

\begin{abstract}
It is known that localized injury to the integument of diapausing silkmoth pupae causes an increase in the respiratory metabolism of an insect as a whole. In the present study, this 'injury metabolism' has been analysed in an individual tissue, the wing epidermis, both in terms of the oxygen consumption of the isolated intact wing, and through measurement of the activities of several oxidative cnzyme systcms in mitochondrial-microsomal preparations derived from homogenates of wing.

The participation of the wing in the respiratory response of the pupa is clearly evident from both types of experiment. The oxygen consumption of isolated wings is a linear function of that of the pupa and shows a corresponding increase after injury. Moreover, an increase of several fold is observed in the activities of cytochrome $c$ oxidase, DPNH-, TPNH-, and succinatecytochrome $c$ reductase, and DPNH oxidase systems. The enzymatic changes appear to be associated with an increase in concentration of respiratory enzymes, similar in character and magnitude to that observed in the uninjured silkmoth when diapause is terminated.

The oxygen consumption of the isolated wing also typifies the behaviour of the pupa as a whole in showing a substantial resistance to inhibition by carbon monoxide. In the intact pupa and in the isolated wing, the degree of sensitivity to this agent increases as a function of the prior respiratory rate in air. Thus the wings of injured pupae, whose respiration is augmented, exhibit greater sensitivity to carbon monoxide than do those isolated from uninjured diapausing pupae. These findings are considered in relation to the 'excessoxidase' hypothesis whereby cytochrome oxidase has previously been proposed
\end{abstract}

* This investigation was supported in part by Public Health Service Research Grant GM-06101, from the Division of General Medical Sciences, and by the Faculty Research Fund, Horace H. Rackham School of Graduate Studies, The University of Michigan; and in part by Public Health Service Research Grant AI-04291, from the National Institute of Allergy and Infectious Diseases, and by funds from the University of Massachusetts Research Council. We gratefully acknowledge helpful discussions of this work with Professors Rowland H. Davis and Carroll M. Williams, as well as valuable technical assistance from Margaret Wrrgau and William D. Butterfield. We thank Professor Gerard R. WYATt for helpful criticism of the manuscript. 
to function as a carbon monoxide-resistant terminal oxidase in pupal tissues. The present findings are in accord with the hypothesis but do not rule out other explanations for the mechanism of resistance to carbon monoxide.

The alterations in respiratory rate and enzyme concentration are of interest in relation to general problems of metabolic control in animal cells and, in particular, the control of specific protein synthesis. The increase in concentration and activity of respiratory enzymes after injury is correlated functionally with the enhanced biosynthetic activity that prevails at this time. Synthesis of respiratory enzymes is viewed as the action of an intracellular regulatory device to maintain a balance of exergonic and endergonic functions under the altered conditions of biological maintenance imposed by injury.

\section{INTRODUCTION}

IN 1953, SchNeIDERMAN and Williams reported the striking alterations in respiratory metabolism which follow localized injury to the integument of diapausing silkmoth pupae. In the case of large injuries, they detected more than a fivefold rise in respiratory rate over a period of several days, a persistence of respiration at the elevated level for at least several weeks, and an eventual decline in metabolism toward the initial level. During the ensuing years, it has become increasingly clear that these respiratory responses are but one aspect of a broad series of biochemical changes evoked by injury. Thus, injury metabolism, as the phenomenon has come to be termed (Schneiderman and Williams, 1953), is now known to embrace substantial increases in biosynthetic activity as measured via the incorporation of labelled precursors into proteins and nucleic acids of several pupal tissues (Telfer and Williams, 1960; Stevenson and Wyatt, 1962; SkinNer, 1963; Wyatt, 1963a; Bowers and Williams, 1964).

These events are of current biological interest and importance for several reasons. In the first place, by virtue of the very low levels which characterize respiratory metabolism and biosynthesis in the uninjured diapausing pupa and the large increases that follow wounding, the phenomenon of injury metabolism would appear to provide favourable opportunity for an experimental approach to mechanisms controlling metabolic rates and biosynthetic activity in animal cells. Moreover, many of the known biochemical responses to injury closely resemble those which are promoted by the growth hormone, ecdysone, when the latter acts to cause the termination of diapause and the concomitant resumption of developmental progress. In view of the biochemical similarities in the insect's response to ecdysone and that to injury, the analysis of injury metabolism has assumed an important position in our efforts to understand how ecdysone exercises its control over the growth process.

The present communication is the second of a series of studies in which injury metabolism is exploited as a route of approach to the physiological and developmental problems just mentioned. In the preceding paper of the series, HARVEY and Williams (1961) have provided insight into the induction and transmission of injury metabolism through respirometric studies on the pupa as a whole. For present purposes, attention is directed to the respiratory responses of an individual tissue, the wing epidermis. Our aim has been to characterize the 
events induced by injury at several levels of biological organization. To this end, we have utilized manometric methods to provide a comparison between the respiratory metabolism of the intact pupa and that of the isolated wing epidermis. In addition, we have carried out spectrophotometric measurements of the activities of several oxidative enzyme systems in particulate preparations isolated from homogenates of wing.

The wing epidermis possesses a number of advantages for this type of approach. Previous studies have shown that it provides sufficient material for enzymatic analyses and that it undergoes alterations at the onset and termination of pupal diapause which are typical of the insect's heart and nonmuscular tissues (SHAPPIRIO and Williams, 1957a, b). Moreover, it is clear that the biosynthetic activity of this tissue responds markedly to integumental injury (SKINNER, 1963; WYATT, 1963a). Finally, the wing's structure is well suited for studies on isolated but intact tissue. As described by KöHLER (1932), the pupal wing consists of a bloodfilled tracheated sac, each wall of which is a simple, cuticularized epithelial layer. One can excise the wing from the pupa, leave the cuticle attached to one epithelial surface, and strip it from the other surface. The latter then becomes directly exposed to any medium in which the tissue is placed. In effect, the net result is a natural tissue slice that, aside from haemocytes and connective tissue components, is but two cell layers in thickness.

\section{Experimental animals}

\section{MATERIALS AND METHODS}

Experiments were performed on diapausing pupae and developing adults of the Cecropia silkmoth, Hyalophora cecropia (L.), and on diapausing pupae of the Polyphemus silkmoth, Antheraea polyphemus (Cramer). In certain cases, the pupae were stabilized in permanent diapause by surgical removal of their brains at least 1 month prior to use (WilliaMs, 1946). All animals were maintained at $25^{\circ} \mathrm{C}$.

\section{Injuries to experimental animals}

Standardized large injuries were established on individual pupae according to the technique previously described (HarveY and Williams, 1961). In essence, this procedure involved removal of the integument of the leg and facial region from $\mathrm{CO}_{2}$-anaesthetized pupae, followed by excision of the underlying epidermis and leg Anlagen. Crystalline phenylthiourea and streptomycin sulphate were implanted into the body cavity to serve as antityrosinase and antibacterial agents. The wound was then filled with insect Ringer (EPHrussi and BEADLE, 1936) and covered by a plastic window sealed in place with melted paraffin. The injured animals were returned to air and stored at $25^{\circ} \mathrm{C}$.

\section{Manometric studies on intact pupae}

Measurements of oxygen uptake in air were performed at $25^{\circ} \mathrm{C}$ using the modified Warburg technique described previously (SchNEIDERMAN and Williams, 1953; HARVEY and WilliaMs, 1961). The rate of oxygen uptake $\left(Q_{\mathrm{O}_{2}}\right)$ was expressed 
as cubic millimetres oxygen consumed per gram live pupal weight per hour or as cubic millimetres per milligram pupal dry weight per hour.

The assessment of oxygen uptake in carbon monoxide-oxygen mixtures was also made from manometric measurements at $25^{\circ} \mathrm{C}$. The data were corrected for the non-enzymatic reactions of carbon monoxide and for enzymatic oxidation of carbon monoxide, according to the procedures of HakveY (1961). The results were confirmed by calculations based on direct analyses of gases in the manometers at the initiation and conclusion of critical experiments (ScHOLANDER, 1947).

\section{Studies on isolated wings}

A. Isolation of wings. An incision was made through the external pupal integument along the entire circumference of the forewing. This incision was continued along the line separating the wing from the antenna, and across the base of the wing where the latter joins the mesothorax. The wing was then grasped with forceps at its transected base and gently lifted free, as a flattened sac of epithelium still attachcd to the cxternal cuticle. The other forewing was isolatcd in like manner.

B. Transfer of wings to flasks; diluted blood. A standard procedure was developed for transferring the isolated wings to Warburg vessels for measurements of gas uptake. The tip of the abdomen of the donor animal was excised and approximately $1 \mathrm{ml}$ of blood drained into a centrifuge tube containing crystals of phenylthiourea. The blood was centrifuged and $0.5 \mathrm{ml}$ of the cell-free supernatant transferred to an ice-cold beaker containing $1.5 \mathrm{ml}$ of insect Ringer (EPHRUss and BEADLE, 1936), buffered at $\mathrm{pH} 7.0$ with $2.5 \mathrm{mM}$ phosphate. A volume of $0.7 \mathrm{ml}$ of this diluted blood (corresponding to about $0.17 \mathrm{ml}$ of undiluted blood) was transferred to a standard $5 \mathrm{ml}$ Warburg vessel containing $0.1 \mathrm{ml}$ of a solution of $0.02 \%$ streptomycin sulphate in buffered Ringer. As each anterior wing was excised it was placed in the beaker containing the diluted blood previously drawn from the same individual. 'The pair of wings was then immediately removed from the beaker and placed in the Warburg vessel. Alkali was added to the filter paper in the centre well and the rate of oxygen consumption determined as described below.

C. Alternate transfer procedures and fluid media. For certain experiments the wings were rinsed in blood-free buffered Ringer. In the experiments described as being performed in the presence of Krebs's substrates, the haemolymph was replaced by $0.15 \mathrm{ml}$ of a solution containing $32 \mathrm{mM}$ sodium pyruvate, $35 \mathrm{mM}$ sodium fumarate, $32 \mathrm{mM}$ sodium L-glutamate, and $75 \mathrm{mM}$ D-glucose. 'The final concentrations within the Warburg vessel were identical with those in the 'serum substitute' defined by KREBS (1950).

D. Oxygen uptake in air. 'The pair of wings, which occupied approximately $0.15 \mathrm{ml}$ in volume, were transferred as described above to standard $5 \mathrm{ml}$ Warburg vessels equipped with side-arm and venting plug. The fluid in the vessel consisted of $0.80 \mathrm{ml}$ of one of the media just described. A small folded slip of Whatman No. 40 filter paper, moistened with $0.05 \mathrm{ml}$ of $1 \mathrm{~N}$ potassium hydroxide, was 
placed in the centre well of the vessel to absorb respired carbon dioxide. The total displacement of wings, medium, and alkali was $1.0 \mathrm{ml}$.

The vessels were positioned in a water bath maintained at $25^{\circ} \mathrm{C}$ and were shaken at $140 \mathrm{c} / \mathrm{min}$. Measurements of oxygen uptake were made at intervals of $\frac{1}{2} \mathrm{hr}$ to $8 \mathrm{hr}$ depending on the duration of experiments, which ranged from 5 to $24 \mathrm{hr}$. At the conclusion of each experiment, the wing epidermis was teased free from cuticle, rinsed in distilled water, and desiccated for 1 day at $25^{\circ} \mathrm{C}$ over concentrated sulphuric acid. The rate of oxygen uptake $\left(Q_{\mathrm{O}_{9}}\right)$ was expressed either as cubic millimetres of oxygen consumed per milligram dry weight of epidermis per hour or as cubic millimetres of oxygen per wing per hour.

E. Gas uptake in carbon monoxide-oxygen mixtures. The total gas uptake of isolated wings in carbon monoxide-oxygen mixtures was measured by the technique just described. Gas mixtures were prepared in a spirometer. 'Twenty volumes of the mixture were passed through the manometer, into the main vessel and out via the side-arm and venting plug. The gas mixture was sealed within the manometer and vessel at atmospheric pressure. The thermobarometer was flushed with the same gas mixture; by this procedure it was possible to correct manometric measurements to compensate not only for fluctuations of temperature and barometric pressure, but also for the reaction of carbon monoxide with alkali (HARVEY, 1961).

\section{Spectrophotometric measurements of oxidative enzyme systems in wing homo- genates}

A. Preparation of homogenates. For the analyses described below, the wings of several Cecropia pupae were pooled. In the case of uninjured or injured pupae, six to nine animals afforded sufficient material. In experiments on developing adults two or three animals sufficed. Wings from the appropriate number of individuals were excised, teased free of cuticle in ice-cold $320 \mathrm{mM}$ sucrose containing phenylthiourea, and briefly rinsed in additional ice-cold sucrose. They were homogenized in a final volume of $5.0 \mathrm{ml}$ in $320 \mathrm{mM}$ sucrose, by means of twenty up-down strokes of a previously chilled Teflon pestle rotating at 1000 $\mathrm{rev} / \mathrm{min}$ in a corresponding glass vessel (clearance $0.13 \mathrm{~mm}$ ). The tissue grinder was kept in crushed ice during this process. The resulting homogenate was then subjected to differential centrifugation as detailed below.

The original homogenate was first centrifuged at a field-time integral (De Duve and BeRThet, 1954) of $4000 \mathrm{~g}$-min, using a Servall RC-1 centrifuge whose SS-34 rotor was maintained at $0^{\circ} \mathrm{C}$. The sediment was washed by resuspension in $2.0 \mathrm{ml}$ of $320 \mathrm{mM}$ sucrose followed by recentrifugation at $4000 \mathrm{~g}$-min. These initial centrifugations served to sediment nuclei and other large particulate matter while leaving most of the mitochondria and smaller particles in suspension. By means of analysis of cytochrome $c$ oxidase activity, which is believed to be confined to the mitochondria and therefore capable of serving as a marker for these organelles, it was possible to confirm that at least 90 per cent of the mitochondrial material in the original homogenate was retained in the combined 
supernatants. The latter were then centrifuged at $2 \cdot 1 \times 10^{6} \mathrm{~g}$-min in the No. 40 rotor of a Spinco model L ultracentrifuge. The resulting mitochondrial-microsomal pellet was washed by gentle resuspension in $5.0 \mathrm{ml}$ of $320 \mathrm{mM}$ sucrose and recentrifugation at $2 \cdot 1 \times 10^{6} \mathrm{~g}$-min. The final sediment was resuspended in a total volume of $2.0 \mathrm{ml}$ of $320 \mathrm{mM}$ sucrose and used directly for analysis.

B. Enzymatic assays. The following oxidative enzyme systems were studied: (a) DPNH oxidase; (b) succinate-cytochrome $c$ reductase; (c) DPNH-cytochrome $c$ reductase; (d) TPNH-cytochrome $c$ reductase; and (e) cytochrome $c$ oxidase. The activity of each system was determined in a Beckman model DU spectrophotometer, in terms of changes in absorbance associated with oxidation or reduction of exogenous DPNH or cytochrome $c$. Each determination was carricd out in a total volume of $1.0 \mathrm{ml}$, which included a final concentration of $0.1 \mathrm{M}$ phosphate buffer, $\mathrm{pH} 7 \cdot 2$, as well as the mixture of enzyme preparation and reagents appropriate for the particular type of assay.

DPNH oxidase and cytochrome $c$ oxidase activities were measured as described by Shappirio and Williams (1957b). Cytochrome $c$ reductase activities were also assessed in the manner described previously (SHAPPIRIo and Williams, 1957b), except that the final concentration of cytochrome $c$ was increased to $60 \mu \mathrm{M}$. In the DPNH-linked reductase system, the final concentration of DPNH was increased to $160 \mu \mathrm{M}$. These increased concentrations were found to afford better linearity in the present experiments. Measurements of TPNH-cytochrome $c$ reductase activity were carried out in a fashion identical with that used in the case of the DPNH-linked system, but with the DPNH replaced by a final concentration of $160 \mu \mathrm{MI}$ TPNH.

These conditions afforded a linear change in optical density, which was then expressed as millimicromoles DPNH or cytochrome $c$ oxidized or reduced per milligram nitrogen per minute. The nitrogen content of the mitochondrialmicrosomal preparations was estimated spectrophotometrically by means of the Folin-Ciocalteu reagent as described previously (ShaPpIRIo and WiLliaMs, 1957b). The validity of this procedure for nitrogen determinations was reaffirmed by construction of a calibration curve on which were plotted the results of parallel Folin-Ciocalteu and $\mathrm{Kjeldahl}$ nitrogen analyses. The latter were carried out on representative mitochondrial-microsomal preparations from wings of uninjured and injured pupae as well as developing adults at the stages used in this study. When Folin-Ciocalteu determinations were carried out in the range of 3-25 $\mu \mathrm{g}$ equivalent Kjeldahl nitrogen, a single straight line was obtained, showing a constant proportionality between the values yielded by the two methods, and confirming the previous findings of SHAPPIRIO and WILliams (1957b) based on whole homogenates.

\section{Gases and reagents}

Oxygen, nitrogen, and carbon monoxide were obtained commercially and handled as described by Harver and Williams (1958b). Cytochrome $c$ was purchased from Sigma Chemical Company, St. Louis; this product was prepared 
from horse heart and was supplied at a stated purity of 90-100 per cent based on molecular weight 12,270 . Before use in the present studies, the cytochrome was further purified by chromatography on Amberlite XE-64 resin (MARGOLIASH, 1954) to yield solutions of the oxidized and of the reduced forms, which were then maintained at $-10^{\circ} \mathrm{C}$ for periods up to 1 month. Enzymatically reduced DPNH and TPNH were also obtained from Sigma, at stated purities of at least 96 and 90 per cent, respectively, and were used directly, with handling to minimize the formation of endogenous inhibitors (FAWCETT et al., 1961). Other chemicals used in the present study were of best commercially available biochemical or analytical reagent quality.

\section{EXPERIMENTAL RESULTS}

\section{Oxidative enzyme systems in wings of injured pupae}

It was already apparent, at the outset of the present study, that the overall respiratory response of diapausing pupae to injury closely resembled that observed when diapause is terminated by ecdysone. We were therefore led to enquire whether oxidative enzyme systems in individual pupal tissues experience changes after injury which likewise resemble those known to occur at the termination of diapause. For this enquiry, a total of 108 unchilled diapausing pupae from a single batch of harvested Cecropia cocoons were used. From these pupae, forty-eight individuals were subjected to the standardized leg-and-face injury, and were then subdivided into groups of six. Four groups were sacrificed approximately 1 week (6-8 days) later, and their wings pooled and subjected to analysis. The additional four groups of injured pupae were similarly analysed approximately 8 weeks (54-60 days) after injury. Three injured pupae died and were discarded, reducing the size of certain groups to five individuals. The remaining, uninjured, pupae served as controls. The results of spectrophotometric analysis of five enzyme systems are summarized in Table 1. Although considerable variability is encountered from group to group, especially among diapausing pupae, it is clear that injury is followed by pronounced alterations in activity for each of the enzyme systems studied. One week after injury, the activities are substantially increased above the low levels that characterize homogenates prepared from the wings of uninjured diapausing pupae. On the basis of the specific activities reported in Table 1, this increase is twofold to threefold in the case of the DPNH oxidase and cytochrome $c$ reductase systems, and nearly fivefold in the case of cytochrome $c$ oxidase. The increase is particularly striking for the DPNH oxidase system; the latter is indetectable or barely detectable in preparations from uninjured pupae and is invariably detectable at substantial levels in pupae 1 week after injury.

The values of $P$ shown in Table 1 were derived by application of the MannWhitney U test (SIEGEL, 1956), and serve to estimate the probabilities that the series of results from injured and from uninjured pupae belong to the same numerical population. Except in the case of the TPNH-cytochrome $c$ reductase system, these results show differences which are significant at the 1 per cent level. 
TABle 1-Oxidative enzyme SYSTEMS IN WING EPIDERMis FROM UNINJURED AND INJURED CECROPIA PUPAE AND DEVELOPING ADULTS

\begin{tabular}{|c|c|c|c|c|c|c|}
\hline Animals & DO & SCR & DCR & TCR & $\mathrm{CO}$ & Number \\
\hline $\begin{array}{l}\text { Uninjured diapausing } \\
\text { pupae }\end{array}$ & $\begin{array}{r}6 \cdot 6 \\
<2 \cdot 2 \\
7 \cdot 2 \\
<2 \cdot 2 \\
6 \cdot 6 \\
4 \cdot 0 \\
6 \cdot 0 \\
3 \cdot 2\end{array}$ & $\begin{array}{l}17 \\
10 \\
22 \\
23 \\
22 \\
16 \\
17 \\
43\end{array}$ & $\begin{array}{r}100 \\
58 \\
74 \\
110 \\
68 \\
63 \\
97 \\
110\end{array}$ & $\begin{array}{l}- \\
- \\
32 \\
19 \\
22 \\
25 \\
63\end{array}$ & $\begin{array}{r}170 \\
250 \\
- \\
280 \\
210 \\
90 \\
190 \\
440\end{array}$ & $\begin{array}{l}6 \\
6 \\
6 \\
9 \\
9 \\
9 \\
9 \\
6\end{array}$ \\
\hline Mean \pm av. dev. & $4 \cdot 8 \pm 1 \cdot 9$ & $21 \pm 6$ & $85 \pm 19$ & $32 \pm 12$ & $230 \pm 77$ & \\
\hline $\begin{array}{l}\text { Pupae } 1 \text { week after } \\
\text { injury }\end{array}$ & $\begin{array}{l}12 \\
13 \\
11 \\
10\end{array}$ & $\begin{array}{l}42 \\
46 \\
35 \\
42\end{array}$ & $\begin{array}{l}200 \\
230 \\
200 \\
230\end{array}$ & $\begin{array}{l}\frac{78}{63} \\
90\end{array}$ & $\begin{array}{r}1000 \\
1100 \\
840 \\
1100\end{array}$ & $\begin{array}{l}6 \\
6 \\
5 \\
6\end{array}$ \\
\hline $\begin{array}{l}\text { Mean } \pm \text { av. dev. } \\
P\end{array}$ & $\begin{array}{l}12 \pm 1 \\
0.002\end{array}$ & $\begin{array}{l}41 \pm 3 \\
0 \cdot 014\end{array}$ & $\begin{array}{c}220 \pm 15 \\
0.002\end{array}$ & $\begin{array}{l}77 \pm 9 \\
0 \cdot 027\end{array}$ & $\begin{array}{c}1000 \pm 90 \\
0 \cdot 003\end{array}$ & \\
\hline $\begin{array}{l}\text { Pupae } 8 \text { weeks after } \\
\text { injury }\end{array}$ & $\begin{array}{c}6 \cdot 0 \\
- \\
-\end{array}$ & $\begin{array}{l}19 \\
42 \\
30 \\
35\end{array}$ & $\begin{array}{r}130 \\
130 \\
84 \\
130\end{array}$ & $\begin{array}{l}58 \\
58 \\
30 \\
63\end{array}$ & $\begin{array}{l}470 \\
430 \\
330 \\
510\end{array}$ & $\begin{array}{l}6 \\
5 \\
5 \\
6\end{array}$ \\
\hline $\begin{array}{l}\text { Mean } \pm \text { av. dev. } \\
P\end{array}$ & $\begin{array}{c}8 \cdot 5 \pm 2 \cdot 5 \\
0 \cdot 166\end{array}$ & $\begin{array}{l}33 \pm 7 \\
0 \cdot 077\end{array}$ & $\begin{array}{c}120 \pm 17 \\
0 \cdot 024\end{array}$ & $\begin{array}{c}52 \pm 11 \\
0 \cdot 119\end{array}$ & $\begin{array}{c}440 \pm 55 \\
0.012\end{array}$ & \\
\hline $\begin{array}{l}\text { Developing adults } \\
\text { (first to second day) }\end{array}$ & $\begin{array}{r}5 \cdot 6 \\
9 \cdot 0 \\
8 \cdot 0 \\
7 \cdot 2 \\
8 \cdot 0 \\
10 \cdot 0\end{array}$ & $\begin{array}{l}28 \\
38 \\
37 \\
38 \\
58 \\
90\end{array}$ & $\begin{array}{l}140 \\
230 \\
140 \\
160 \\
200 \\
190\end{array}$ & $\begin{array}{r}50 \\
44 \\
25 \\
79 \\
130 \\
120\end{array}$ & $\begin{array}{r}1100 \\
1600 \\
1200 \\
790 \\
1300 \\
1600\end{array}$ & $\begin{array}{l}3 \\
3 \\
3 \\
3 \\
3 \\
2\end{array}$ \\
\hline $\begin{array}{l}\text { Mcan } \pm \text { av. dev. } \\
P^{\prime}\end{array}$ & $\begin{array}{c}8 \cdot 0 \pm 1 \cdot 3 \\
0 \cdot 010\end{array}$ & $\begin{array}{l}48 \pm 17 \\
0 \cdot 457\end{array}$ & $\begin{array}{c}180 \pm 30 \\
0 \cdot 057\end{array}$ & $\begin{array}{c}75 \pm 35 \\
0 \cdot 452\end{array}$ & $\begin{array}{c}1300 \pm 240 \\
0.086\end{array}$ & \\
\hline
\end{tabular}

$\mathrm{DO}=\mathrm{DPNH}$ oxidase (units of activity, millimicromoles DPNH oxidized $/ \mathrm{min} / \mathrm{mg}$ nitrogen). SCR, DCR, TCR $=$ succinate, DPNH, TPNH-cytochrome $c$ reductases (units of activity, millimicromoles cytochrome $c$ reduced $/ \mathrm{min} / \mathrm{mg}$ nitrogen). $\mathrm{CO}=\mathrm{Cyto-}$ chrome $c$ oxidase (units of activity, millimicromoles cytochrome $c$ oxidized/min $/ \mathrm{mg}$ nitrogen). Activities measured on mitochondrial-microsomal pellet derived from the pooled wings of the number of animals indicated in the right-hand column. When DPNH oxidase was below detectable level, table records 'less than' the activity which would have been detectable under the conditions of experiment. For purposes of averaging, the minimal detectable levels were included.

$P=$ Probability (Mann-Whitncy test) of idcntity of numcrical population shown with that observed in uninjured pupae.

$P^{\prime}=$ Same, but with reference to pupae 1 week after injury. 
In the case of TPNH-cytochrome $c$ reductase, with a smaller number of measurements available for comparison, the confidence level is about 3 per cent.

It is also evident from Table 1 that the levels of activity 8 weeks after injury are lower than those just described for wings of pupae studied sooner after injury. Although the average levels of activity still appear to be somewhat higher than those of wings from uninjured pupae, there is considerable overlap in individual cases for several enzyme systems and it is more difficult to distinguish individual measurements from those carried out on uninjured pupae. 'This fact is reflected in the increased values of $P$ recorded in Table 1, which compares activities 8 weeks after injury with those recorded from uninjured pupae.

It is of particular interest to compare the changes after injury with those that accompany the termination of diapause and the initiation of adult development. In order to provide information on this point, we have included the results from a series of enzymatic analyses on wings of normal uninjured Cecropia pupae at the outset of adult development. These individuals belonged to the same batch from which those utilized above wcrc originally drawn, and were caused to initiate development at $25^{\circ} \mathrm{C}$ following 16 weeks' exposure at $6^{\circ} \mathrm{C}$ (Williams, 1956). As shown in Table 1 , the activities in wings of these developing individuals are greater than those recorded during diapause. We may summarize the nature of the changes by stating that the increases after injury are of substantially the same character and magnitude as is encountered in the transition from diapause to the outset of adult development. In the case of DPNH oxidase, it appears that the response to injury slightly exceeds that which occurs when ecdysone evokes the termination of diapause. In all cases except that of DPNH oxidase, statistical comparison of values recorded from the injured pupae and developing adults shows substantially increased probabilities that the values are from indistinguishable numerical populations.

\section{The inhibition of the injury metabolism by carbon monoxide}

As reported in the previous section, the enhanced overall metabolism of the injured pupa is reflected in substantial increases in activity of oxidative enzyme systems in an individual tissue such as the wing. If such increases in activity are paralleled in vivo for the pupa as a whole, they should lead to an enhanced sensitivity of the pupa's respiration to carbon monoxide (HARvEY and WILliams, 1958b; KurLand and SchneIderman, 1959). Furthermore, the more the metabolism is enhanced by injury the more one would expect it to be inhibited by carbon monoxide. The first prediction was realized by HaRver and ShappIRIo (Harvey, 1956) and the second by Kurland and Schneideriman (1959) in terms of the total gas uptake. HakvEY (1961) resolved the total gas uptake into a component attributable to true respiration and a component attributable to carbon monoxide combustion and showed how the total gas uptake could be corrected for the latter. The carbon monoxide-sensitivity of the true respiration of both injured and uninjured pupae may now be examined. The rate of gas uptake was measured (a) for cach of scven pupac in $82 \%$ atm carbon monoxide and $18 \%$ atm 
oxygen $\left(\mathrm{CO} / \mathrm{O}_{2}\right.$ ratio $\left.4.6 / 1\right)$; (b) for each of thirteen pupae in $90 \%$ atm carbon monoxide and $10 \%$ atm oxygen (9/1); and (c) for each of ten pupae in $500 \%$ atm carbon monoxide and $21 \%$ atm oxygen (24/1). These data, corrected for nonspecific reactions of carbon-monoxide, were reported by Harvey (1961). In Fig. 1

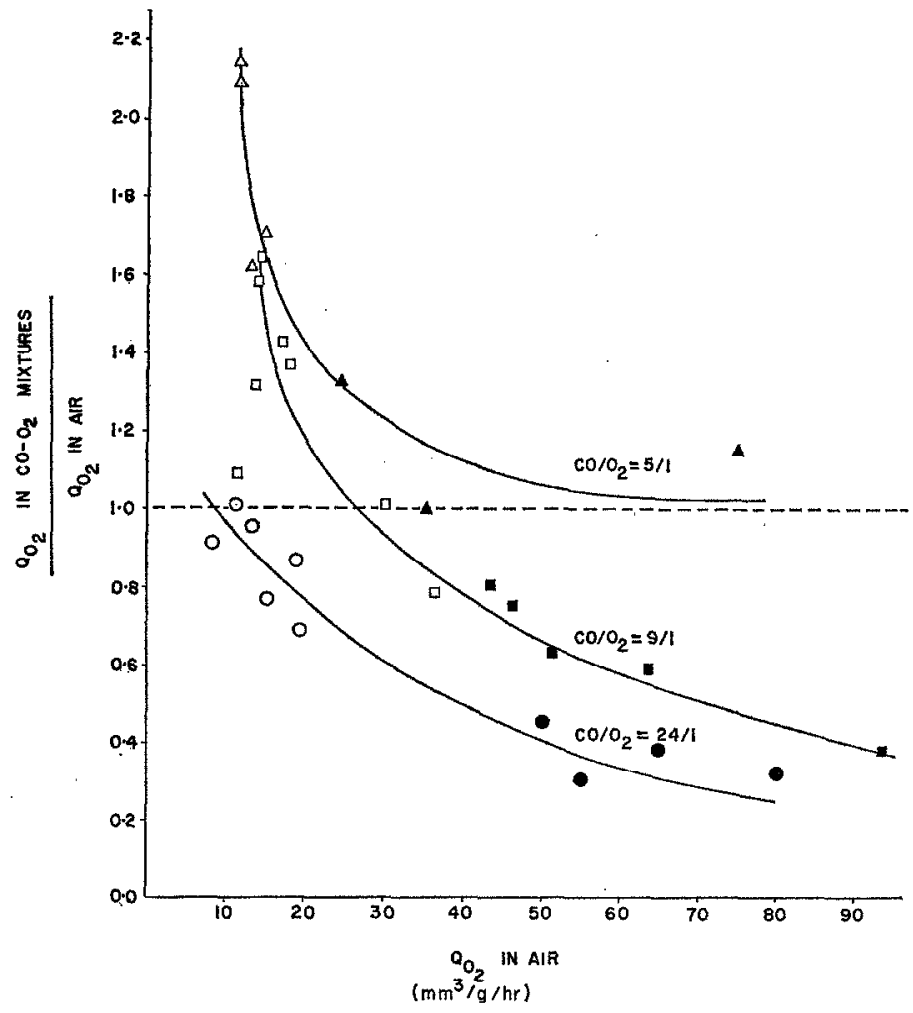

Fig. 1. The effects of carbon monoxide on the oxygen uptake of diapausing pupae. The rate of oxygen uptake in each of three $\mathrm{CO}-\mathrm{O}_{2}$ mixtures is divided by the rate in air and plotted as a function of the rate in air. Thus, points above the dotted line signify a stimulation of respiration; those below the line an inhibition. The open symbols represent data from uninjured pupae; the closed symbols represent data from injured pupae. At $\mathrm{CO} / \mathrm{O}_{2}$ ratios of $9 / 1$ and $24 / 1$ the respiration of injured pupae is invariably inhibited by carbon monoxide, the degree of inhibition increasing as a function of the increased oxygen consumption in air.

the results corrected for gas uptake due to carbon monoxide combustion as well are replotted. The ratio of oxygen uptake in the $\mathrm{CO}-\mathrm{O}_{2}$ mixtures relative to the oxygen uptake in air is plotted as a function of the oxygen uptake in air. At low $Q_{\mathrm{O}_{2}}$ 's, the stimulation of oxygen uptake in $\mathrm{CO}-\mathrm{O}_{2}$ mixtures is due to a stimulation of the true respiration of the pupa (HaRveY, 1961).

For present purposes, attention is directed to the portion of each curve below the dotted line, i.e. in the region where the true respiration is inhibited. At 
$\mathrm{CO} / \mathrm{O}_{2}$ ratios of $9 / 1$ or greater, the respiration of the injured pupae invariably is inhibited by carbon monoxide. Moreover, the degree of inhibition is augmented systematically as a function of the enhanced metabolism displayed in air.

The clear-cut carbon monoxide-sensitivity of the respiration of the injured pupa supports the argument that the enhancement of metabolism following integumentary injury is made possible by an increase in the activity of the respiratory

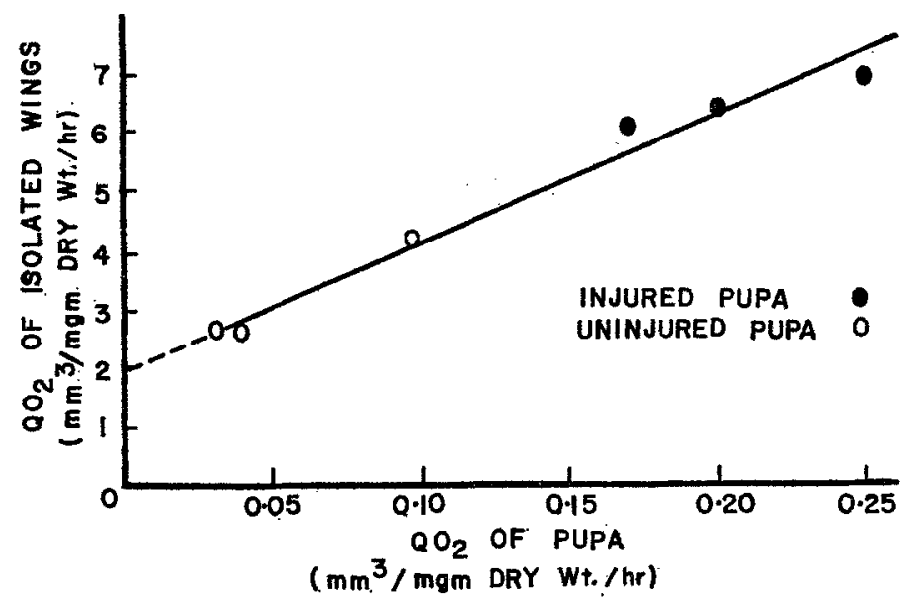

FIG. 2. The $Q_{\mathrm{O}_{2}}$ in air of wings isolated from uninjured (open circles) and injured (closed circles) diapausing pupae of the Polyphemus silkmoth is plotted as a function of the $Q_{\mathrm{O}_{2}}$ of the corresponding intact pupa in air. Values for wings from both injured and uninjured pupae fall on the same straight line.

chain. This observation finds a seemingly exact parallel in the carbon monoxidesensitivity of the enhanced respiratory metabolism of the developing adult (SCHNEIDERMaN and Williams, 1954).

\section{Injury metabolism in isolated wings}

In order to link the enzymatic data previously considered in Section 1 with the whole-animal studies described in Section 2, the respiratory metabolism of isolated but intact wings was compared in three uninjured Polyphemus pupae and three pupae of the same species which had been injured 1 week previously. In each of these six cases, the anterior wings of a pupa were excised and paired without rinsing in a manometer vessel containing diluted blood as described in Method 4B.

During the first $6 \mathrm{hr}$ after isolation, the $Q_{\mathrm{O}_{2}}$ of the isolated wings was reasonably constant. The average $Q_{\mathrm{O}_{2}}$ for the wings from previously injured pupae was 6.5-a value twice that of the wings from previously uninjured pupae (Fig. 2). Thus the high metabolism displayed by the pupa as a whole after extensive injury appears to be reflected in the metabolism of wings isolated from previously injured pupae. 
In Fig. 2, the $Q_{\mathrm{O}_{2}}$ of each of the six wing pairs is plotted as a function of the $Q_{\mathrm{O}}$ of the corresponding pupa. It is clear that the respiration of the isolated wings bears a linear relationship to that of the intact pupa. However, the curve does not

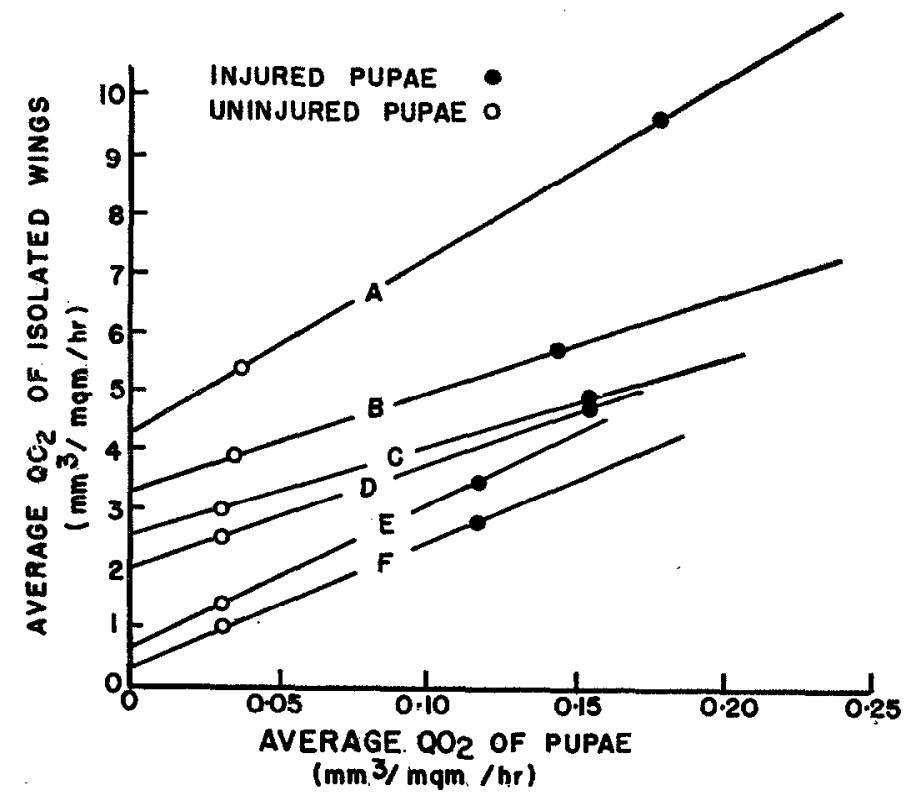

Frg. 3. Effects of increasing the time of rinsing in ice-cold Ringer on the $Q_{\mathrm{O}_{2}}$ of wings from diapausing pupae of the Cecropia silkmoth. Each open circle represents the mean from determinations on wings from three previously uninjured pupae; each closed circle the mean from determinations on wings from three previously injured pupae. A and B-two wings rinsed $5 \mathrm{sec}$ and respiration measured in diluted Krebs's substrates; $\mathrm{C}$-one wing rinsed $1 \mathrm{~min}$ and respiration measured in diluted blood from a previously injured pupa; $\mathrm{D}$-one wing rinsed $1 \mathrm{~min}$ and respiration measured in diluted blood from a previously uninjured pupa; $\mathrm{E}$-one wing rinsed $16.5 \mathrm{~min}$ and respiration measured in diluted blood from an uninjured pupa; F-one wing rinsed $16.5 \mathrm{~min}$ and respiration measured in diluted Krebs's substrates. The more thorough the rinsing procedure the lower is the respiration of wings from both uninjured and injured pupae. Following any particular rinsing procedure, the respiration of wings from injured pupae invariably is higher than that of wings from uninjured pupae.

pass through the origin. When the $Q_{\mathrm{O}_{\mathrm{s}}}$ of the intact pupa is zero, the $Q_{\mathrm{O}_{2}}$ of the isolated wings is approximately 2 .

This phenomenon apparcntly depends at least in part on the details of the procedure used in rinsing blood from the isolated wings. In the experiment just reported the wings were rinsed merely by placing them momentarily in diluted haemolymph. In similar experiments performed on six groups of Cecropia pupae, the rinsing period was progressively extended. Each group consisted of three previously uninjured pupae and three pupae which had been injured a week 
before by the removal of the integument overlying the legs. In all cases the measurements of oxygen consumption were continued for a total of $6 \mathrm{hr}$ after the time of wing isolation. In Fig. 3 the average $Q_{\mathrm{O}_{z}}$ of the isolated wings is plotted as a function of the average $Q_{\mathrm{O}_{2}}$ of the donor pupae for each of the six experiments. A straight line has been drawn between the point representing the average for uninjured pupae and the point for injured pupae in each experiment of the series.

On two groups of pupae (A and B) the wings were agitated gently for approximately $5 \mathrm{sec}$ in ice-cold buffered Ringer; the respiration was measured thereafter in the medium containing Krebs's substrates (Fig. 3(A) and (B)). A yellow colour in the flasks at the end of the experiment revealed that the rinsing procedure had failed to remove all the blood and the experiment may be viewed as having been carried out in diluted insect blood. On two further groups $(C$ and $D)$ the wings were agitated for $30 \mathrm{sec}$ in $100 \mathrm{ml}$ of ice-cold Ringer and the agitation repeated in a fresh $100 \mathrm{ml}$ volume of Ringer. Subsequent measurements of $Q_{\mathrm{O}_{2}}$ in Krebs's substrates were depressed below the corresponding levels in experiments $A$ and $B$. ' $I$ 'his effect is evidently attributable to the more vigorous rinsing procedure. In two final experiments $(E$ and $F)$ the rinsing procedure was further prolonged. Each pair of wings was agitated for $30 \mathrm{sec}$ and soaked for $5 \mathrm{~min}$ in $100 \mathrm{ml}$ of ice-cold Ringer. This sequence was repeated twice in fresh Ringer so that the total period in Ringer was $16.5 \mathrm{~min}$. The respiration of both 'injured' and 'uninjured' wings was depressed to an extremely low level by the prolonged soaking and agitation in Ringer. The $\mathrm{Y}$ intercept was now very close to zero (Fig. 3(E) and (F)). Whether the rinsing effects depend on leaching of substrates and coenzymes, from removing some other metabolically active substance, or from some other cause remains unexamined. Despite the depression of metabolism by prolonged rinsing, and whether or not blood was present in the medium, the average respiration of the wings from previously injured Cecropia pupae was invariably higher than that of wings from previously uninjured pupae, confirming the results from Polyphemus pupae.

\section{Increase in respiration of wings isolated from previously uninjured pupae}

In several experiments, the respiratory measurements on isolated wings were continued for as long as $24 \mathrm{hr}$. During this time the rate of oxygen uptake of the wings from previously uninjured pupae drifted gradually upward. By contrast, the wings from previously injured pupae showed no systematic change in rate. A particularly striking example of these tendencies is presented in Fig. 4. In most cases the enhancement of the metabolism of previously uninjured wings was not as dramatic. Nevertheless, for a total of six preparations the average $Q_{\mathrm{O}_{2}}$ of previously uninjured wings during the first $6 \mathrm{hr}$ was $3 \cdot 2 \pm 0 \cdot 6$ (average deviation) and during the eighteenth to twenty-fourth hours $5 \cdot 6 \pm 0 \cdot 9$. By contrast the average $Q_{\mathrm{O}_{2}}$ of three previously injured wing preparations during the first $6 \mathrm{hr}$ was $6 \cdot 5 \pm 0 \cdot 3$ and during the eighteenth to twenty-fourth hours $6 \cdot 8 \pm 0 \cdot 4$. The possibility of bacterial infection was minimized by the antibiotic in the medium. That no infection was established in the fluid phase was confirmed by removing 
the wings from the flasks at the end of the experiment and recording but a barely detectable gas uptake in the fluid left behind. Although the mechanism underlying the increase of $Q_{\mathrm{O}_{z}}$ in previously uninjured wings is unknown, a superficial resemblance to the injury metabolism in intact pupae is evident.

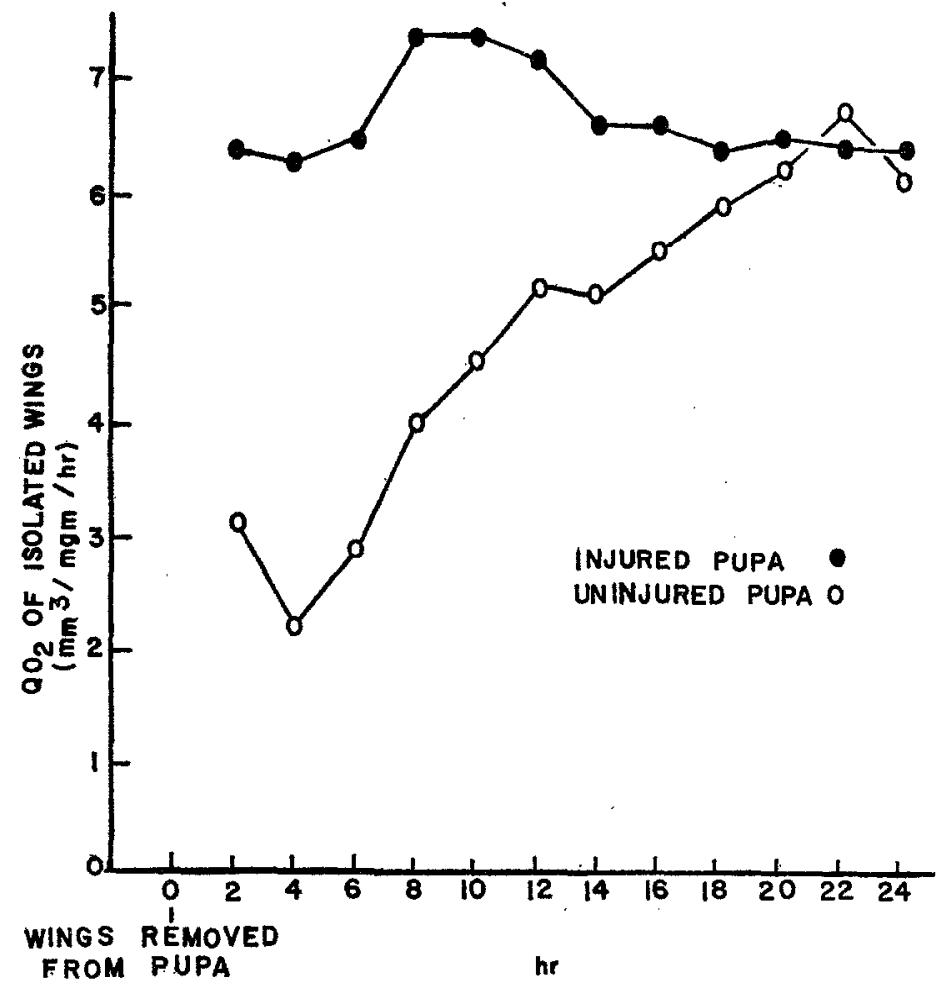

FIG. 4. The open circles record the increase with time of the oxygen uptake of a pair of wings isolated from a normal uninjured Polyphemus pupa. The closed circles record the relatively unchanging time course of the respiration of wings isolated from a previously injured pupa.

5. Effects of carbon monoxide on the respiration of wings isolated from uninjured and injured pupae

Since the wings isolated from previously injured pupae respired at a faster rate than wings from uninjured pupae, one would predict, as in the case of oxygen uptake of the intact pupae, that they would be more sensitive to carbon monoxide. To test this prediction the wings were isolated from each of three normal Cecropia pupae and from each of three pupae which a week previously had been injured by the removal of the integument overlying the legs and face. The respiration was measured for $2 \mathrm{hr}$ in $90 \%$ atm nitrogen and $10 \%$ atm oxygen; for $2 \mathrm{hr}$ in $90 \%$ atm carbon monoxide and $10 \%$ atm oxygen $\left(\mathrm{CO} / \mathrm{O}_{2}=9 / 1\right)$; and, finally, for 
$2 \mathrm{hr}$ in the nitrogen-oxygen mixture. The respiration in each case was partially inhibited by carbon monoxide and this inhibition was reversed in the $\mathrm{N}_{2}-\mathrm{O}_{2}$ mixture.

TABLE 2-CaRbon MONOXIDE INHIBITION OF WINGS ISOLATED FROM PREVIOUSLY INJURED AND FROM PREVIOUSLY UNINJURED DIAPAUSING PUPAE OF THE CECROPIA SILKWORM

\begin{tabular}{|c|c|c|c|c|c|}
\hline \multicolumn{3}{|c|}{$\begin{array}{l}\text { Wings from previously uninjured } \\
\text { diapausing pupae }\end{array}$} & \multicolumn{3}{|c|}{$\begin{array}{l}\text { Wings from diapausing pupae injured } \\
1 \text { week previously }\end{array}$} \\
\hline $\begin{array}{l}\text { No. } \\
\text { of } \\
\text { pupa }\end{array}$ & $\begin{array}{c}Q_{\mathrm{O}_{2}} \text { in } 9 / 1 \\
\mathrm{~N}_{2} / \mathrm{O}_{2} \text { mixture } \\
\left(\mathrm{mm}^{3} / \text { wing } / \mathrm{hr}\right)\end{array}$ & $\begin{array}{l}\% \text { inhibition in } \\
9 / 1 \mathrm{CO} / \mathrm{O}_{2} \\
\text { gas mixture }\end{array}$ & $\begin{array}{l}\text { No. } \\
\text { of } \\
\text { pupa }\end{array}$ & $\begin{array}{c}Q_{\mathrm{O}_{2}} \text { in } 9 / 1 \\
\mathrm{~N}_{2} / \mathrm{O}_{2} \text { mixture } \\
\left(\mathrm{mm}^{3} / \text { wing } / \mathrm{hr} r\right)\end{array}$ & $\begin{array}{l}\% \text { inhibition in } \\
9 / 1 \mathrm{CO} / \mathrm{O}_{2} \\
\text { gas mixture }\end{array}$ \\
\hline $\begin{array}{l}\mathrm{H} .74 \\
\mathrm{H} \cdot 75 \\
\mathrm{H} .78\end{array}$ & $\begin{array}{l}4 \cdot 6 \\
2 \cdot 4 \\
4 \cdot 1\end{array}$ & $\begin{array}{l}28 \\
29 \\
16\end{array}$ & $\begin{array}{l}\text { H.71 } \\
\text { H.72 } \\
\text { H.76 }\end{array}$ & $\begin{array}{l}6 \cdot 2 \\
7 \cdot 0 \\
7 \cdot 8\end{array}$ & $\begin{array}{l}39 \\
42 \\
46\end{array}$ \\
\hline Av. & $3 \cdot 7$ & 27 & Av. & $7 \cdot 0$ & 42 \\
\hline
\end{tabular}

The effects of carbon monoxide have been calculated in terms of the inhibited respiration in carbon monoxide as a percentage of the initial respiration in the $\mathrm{N}_{2}-\mathrm{O}_{2}$ mixture (Table 2). The enhanced respiration of the wings from the injured animals was more sensitive to carbon monoxide than the lower respiration of the wings from the uninjured pupae.

\section{DISCUSSION}

\section{Expression of injury metabolism at the cellular level}

A. Respiratory response of the isolated intact wing epithelium. As measured along the epidermis the wings are situated at a relatively considerable distance from the site of injury. Nevertheless, the metabolic consequences of injury inflicted in the facial and leg region are clearly detectable in the wings. As shown in Fig. 2, the oxygen uptake of wings isolated from uninjured pupae is linearly related to that of the animals from which they were obtained. The same relationship prevails with respect to the wings of injured pupae. In fact, one can describe a single linear function which relates the wing's oxygen consumption to that of the pupa providing the tissue, notwithstanding the normal variations in respiration from one individual to another, and regardless of whether or not the pupa is injured or uninjured. Consequently, there is little reason to doubt that the overall increase which injury evokes in pupal respiration is manifested by a corresponding rise in the oxygen consumption of the wings. Thus, the effects of localized injury are not restricted to the immediate site of wounding. This conclusion is in accord with the findings of a number of investigators who have demonstrated that injury leads to biochemical changes in one or more pupal tissues situated at a distance 
from the site of wounding (Telfer and Williams, 1960; Stevenson and Wyatt, 1962; Skinner, 1963; Wyatt, 1963a; Bowers and Williams, 1964).

B. Effect of injury upon respiratory ensyme concentrations. The above conclusion receives additional support when one considers the enzymatic data obtained in the present study. As we have seen from Table 1 , localized injury is followed by substantial elevations in the activities of five enzyme systems of terminal respiratory metabolism, as compared with the levels of activity that characterize the wings of uninjured pupae. The increases in activity after injury closely resemble those observed when diapause is terminated (Table 1).

Previous studies have shown that the termination of diapause is accompanied by an increasc in the concentrations of respiratory enzymes in the wing epidermis (Shappirio and Williams, 1957a, b). There is reason to believe that the elevated activities of oxidative enzyme systems, observed after injury, also at least in part reflect increases in the concentrations of cytochromes and other components of the respiratory chain. The enzymatic activities reported in Table 1, which are expressed on a nitrogen basis, show substantial increase at the same time that the nitrogen content of the mitochondrial-microsomal fraction used in the analyses also rises by two- to threefold. Moreover, as reported in an earlier communication (SHAPPIRIo, 1960), one can discern spectroscopically an increased intensity of absorption bands of cytochromes $a+a_{3}$ and $b_{5}$ in tissues of injured pupae; and in favourable preparations it is possible to observe faint but definite absorption attributable to cytochrome $c$. These findings argue that cytochrome concentration is increased, and studies are now in progress to provide a quantitative insight. It is already clear from parallel work (SHAPPIRIo, unpublished) that the concentration of DPN in tissues from injured pupae is elevated by several fold above the levels encountered prior to injury.

\section{Effect of carbon monoxide upon respiratory metabolism}

A. Interpretation of data on intact pupa and isolated wing. After suitable corrections to distinguish the effects of carbon monoxide on respiration from other reactions of the gas (HARVEY, 1961), it is clear that the true respiration of the diapausing pupa is stimulated in an atmosphere of $90 \%$ carbon monoxide and $10 \%$ oxygen, provided that the prior rate of respiration in air is less than about $20-25 \mathrm{~mm}^{3} / \mathrm{g} / \mathrm{hr}$ (Fig. 1). When the prior rate of respiration exceeds this range-a circumstance which occasionally occurs in uninjured pupae and which almost invariably prevails in the case of injured pupae-the true respiration is inhibited by carbon monoxide. Moreover, the more that respiration is elevated by injury, the greater becomes the degree of inhibition. Essentially similar results are observed at $\mathrm{CO} / \mathrm{O}_{2}$ ratios other than $9 / 1$; however, as the $\mathrm{CO} / \mathrm{O}_{2}$ ratio is increased, the curve showing the effect of carbon monoxide as a function of prior respiration in air is shifted downward along the ordinate, so that inhibition is encountered at progressively lower prior rates of oxygen consumption in air (Fig. 1).

An essentially similar conclusion is reached when one considers the effect of carbon monoxide upon the oxygen consumption of the isolated wing (Table 2). 
The data on isolated wings are uncorrected for the combustion of carbon monoxide, since this process has as yet been investigated only for the intact pupa (HARveY, 1961). Any such combustion by the wings can only lead to a higher total gas uptake than results from respiration alone. Hence, the finding that total gas uptake is inhibited in the presence of carbon monoxide (Table 2) is clear evidence that the true respiration of wings from injured pupae is sensitive to this agent although the degree of inhibition may have been underestimated.

B. Mechanism of respiratory resistance to carbon monoxide. From the above, we conclude that the degree of inhibition of respiration by carbon monoxide increases as a function of the respiratory rate, whether in the intact pupa or the isolated wing. However, even at the highest levels of respiration encountered, and the greatest $\mathrm{CO} / \mathrm{O}_{2}$ ratios utilized in our studies, inhibition was far from complete. This relative resistance to carbon monoxide has long been known to typify respiratory metabolism in the diapausing silkmoth pupa, and has been the subject of repeated investigations for more than a decade (see reviews by SHAPPIRIO, 1960; HaRveY, 1962). In the most rccent cxperimental studies, evidence was obtained which was interpreted to signify that pupal respiration is mediated by cytochrome oxidase, and that the resistance to carbon monoxide depends on an excess of cytochrome oxidase in relation to the very feeble and otherwise limited respiratory rate (HaRvey and Williams, 1958a, b; Kurland and Schneiderman, 1959). To our knowledge, this type of argument was first voiced with respect to carbon monoxide resistance in living systems by WARBURG (1927). At one time or another it has been applied by many students of respiratory metabolism in animals and plants (KLEIN and RunNSTRÖM, 1940; WolsKy, 1949, 1959; HILL and Hartree, 1953; Yocum and Hackett, 1957; Chance and Hackett, 1959). In essence, this so-called 'excess oxidase' hypothesis holds that when the rate of electron transport in a respiring system is substantially less than the potential turnover of the available cytochrome oxidase, agents like carbon monoxide will fail to exert major inhibitory effect at concentrations which leave sufficient free oxidase to sustain respiration. This explanation differs in principle from other interpretations of carbon monoxide resistance, which invoke the participation of a terminal oxidase other than cytochrome oxidase, and which is unaffected by carbon monoxide, cyanide, etc. In the case of the diapausing pupa, no acceptable evidence for an alternative oxidase has yet been gained. Since there is considerable evidence which supports the excess oxidase hypothesis, we elect to consider our data in accordance with it, while at the same time regarding it as not proven. Certain of our reservations will be apparent from subsequent discussion.

It follows from the excess oxidase hypothesis that experimental manœuvres which elevate respiratory rate should also increase the degree of inhibition encountered with carbon monoxide. The results of the present study are in accord with this requirement, though clearly they are insufficient to constitute a thorough test of the hypothesis. In terms of the excess oxidase hypothesis, we are obliged to infer from our results that, despite the apparent increase in concentration and activity of cytochrome oxidase following injury, there occurs a sufficient rise 
in respiratory activity to yield a greater saturation of the oxidase than normally prevails in the uninjured pupa. This, in turn, would lead to the greater sensitivity to carbon monoxide. However, this explanation is not thoroughly convincing because cytochrome oxidase activity, at least as measured in vitro, is increased after injury by a larger factor than is the activity of the other enzyme systems measured and than is the respiration of the isolated wing. Further resolution of this uncertainty awaits a clearer picture of terminal respiratory pathways operative in pupal tissues. It is possible that the enhanced respiratory activity may be in part attributable to an alteration of the intra-mitochondrial state of respiratory control. In this connexion, the change in sensitivity to carbon monoxide after injury appears at least superficially to resemble that which occurs when mammalian mitochondria, whose electron transfer activity is limited by low concentrations of ADP (State 4 of Chance and Williams, 1956), are provided with ADP. When the latter is limiting, respiration is low and is resistant to inhibitors of cytochrome oxidase (CHANCE and HACKeTt, 1959). But when ADP is provided, sensitivity to inhibitors increases markedly together with the rapid augmentation of respiration. With regard to silkmoth tissues, available data do not yet permit one to discern the degree to which changes in respiratory control states contribute to the observed alterations in resistance to carbon monoxide. This matter merits attention.

In the diapausing Cecropia pupa, one of the major arguments that respiration is mediated by cytochrome oxidase derives from the finding that heart rate and oxygen uptake, which are highly resistant to carbon monoxide at ordinary partial pressures of oxygen, become very sensitive to the inhibitor when oxygen tension is lowered to that of a few millimetres of mercury (HARVEY and WiLliaMs, 1958b; KURLAND and SCHNEIDERMAN, 1959). Lowering of oxygen tension by this amount is in itself without noticeable effect on heart rate or oxygen uptake. We wish to observe that there is an assumption in this argument, as utilized by previous authors, which has not been voiced; namely, that only a single terminal oxidative pathway is operative in pupal tissues at all oxygen tensions, and that this experiment permits one to exclude components other than cytochrome oxidase. Current developments in an allied field of respiratory enzymology may necessitate a re-examination of the matter as it pertains to the diapausing pupa. In recent studies on mitochondrial preparations from a variety of plant tissues, Dr. WALTER BONNER and his associates have been able to define an oxygen-binding and CO-binding cytochrome component other than cytochrome $a_{3}$ (BONNER, 1964; IKUMA et al., 1964). The two components have differing affinities for oxygen; that of the new component being lower than that in the case of $a_{3}$. Information on the relative affinities for carbon monoxide is not yet available. However, the possibility is strongly suggested that at different oxygen tensions, oxygen consumption may be mediated by differing relative proportions of two terminal oxidases, and that the degree of inhibition caused by carbon monoxide may be correspondingly influenced. Further details will await additional characterization of the two pigments. Meanwhile, it seems increasingly prudent to maintain an 
open mind toward the invocation of a simple excess oxidase hypothesis in the tissues of the diapausing silkmoth, and toward the presumed uniqueness of cytochrome $a_{3}$ as terminal oxidase.

\section{Control of respiratory enzyme concentration}

Despite the very low levels of cytochrome encountered in most tissues of the diapausing Cecropia pupa (Williams, 1948; SANBORN and Williams, 1950; SHAPPIRIo and WILLIAMS, 1957a), the insect is capable of substantial increases in its respiration on a short-term basis. This is evident from the immediate rise in respiration that is observed following a puncture wound (HARvEY and Williams, 1961) or from the administration of 2,4-dinitrophenol (KuRLAND and Schneiderian, 1959; Harvey and Shappirio, unpublished). This finding affords preliminary evidence that one or more pupal tissues possess the capacity for rapid increase in respiration, presumably through the release of restraints imposed by respiratory control devices of the customary type; however, the available data are restricted to the intact pupa and thercfore do not nccessarily reflect the contribution of any particular pupal tissues such as the wing epidermis. In any event, it is of particular interest that the rise in respiration associated with development of injury metabolism appears to be underwritten not merely by increased activity of existing respiratory machinery, but, as we have observed in Section 1B of the discussion, by augmented concentrations of oxidative enzymes.

In considering the significance of these increased concentrations, it is perhaps most important to observe that they are functionally correlated with the enhanced energetic requirements of pupal tissues responding to injury or to ecdysone. As previously noted, both injury and ecdysone clearly evoke a marked increase in biosynthetic activities of a variety of tissues including the wings. One obvious possibility is that the endergonic demands of tissues are sufficiently enhanced so that the previously existing energy-coupling systems of pupal tissues are inadequate, even if functioning at maximal rates. According to this view the increased activities of oxidative enzyme systems reported in the present paper for the injured pupa, and as described previously in relation to the termination of diapause (Shappirio and Williams, $1957 \mathrm{~b}$ ), may be viewed as the operation of a regulatory device to augment the pupa's limited capacity for energy coupling, through synthesis of additional oxidative machinery.

An alternative possibility which merits consideration in this context does not require that the pupa's respiratory capacity be inadequate. Rather, it may be that intracellular regulatory devices operate to ensure that the respiratory chain functions at some characteristic fraction of its total potential, at least on the average over a sustained period. Thus, in keeping with sustained increase in endergonic activity, the concentrations of respiratory enzymes may be augmented to permit an increase in the absolute yield of ATP, while maintaining electron transport at a constant fraction of the maximum rate for the respiratory system as a whole. The latter would have the advantage of ensuring reserve capacity to meet shortterm fluctuations in rate of utilization of ATP. 
Quite apart from these particular inferences, the fact that respiratory enzyme concentration in animal tissues is regulated in accordance with other metabolic activities has previously been stressed (e.g. DRABKIN, 1955). Like many current concepts in respiratory enzymology, this realization finds support in Keilin's classic treatise on cytochrome (KEILIN, 1925), wherein it was observed that the more active tissues of living organisms contain higher concentrations of cytochrome. Nevertheless, the actual mechanisms regulating synthesis of respiratory enzymes in this manner are essentially unknown. Indeed, the problem constitutes one aspect of a central question in present-day biology: the control of synthetic rates of specific enzymes.

We may note that an carly conscquence of incrcascd biosynthetic activity in living tissues would be a change in the steady-state levels of ATP and ADP, and of their ratio, unless the tissues possess mechanisms to keep these levels constant. It seems likely that the maintenance of some characteristic value of these levels is critical for ensuring the continued orderly operation of the large number of metabolic reactions which depend on ATP and ADP. Indeed, in the Cecropia silkmoth itself there is evidence in the case of wing and fat body that the ATP/ADP ratio changes only rather slightly during the transition from diapause to development, at a time when the individual nucleotides increase in concentration and when the biosynthetic activity increases enormously (CAREY and WYATT, 1963). In order to maintain the appropriate balance, the cells may adjust their rate of respiration directly, by immediate respiratory control devices, and they may enhance their capacity for energy coupling through the synthesis of additional catalytic components of respiration and oxidative phosphorylation. As we have seen, the latter events appear to accompany the pupa's sustained response to injury and to ecdysone.

In the light of currently developing concepts of the control of enzyme synthesis, it is of interest to conjecture that the production of increased levels of oxidative enzymes involves the interaction of one or more molecules with the enzymeforming machinery, to modify the rates of synthesis. For signalling appropriate information to the synthesizing system, a logical candidate would be either ATP, $\mathrm{ADP}$, or some other molecule whose concentration is altered in response to a change in that of ATP or ADP. The prospect thus seems worthy of attention that ATP and ADP are of critical importance not only in the short-term regulation of metabolic rates (KREBS, 1959), but in the control of respiratory enzyme concentration. This hypothesis would appear to be amenable to analysis by experiments designed to alter the intracellular levels of ATP and ADP over sustained periods.

\section{Injury metabolism in relation to the biochemical action of ecdysone}

Pupal diapause is a state of arrested development upon which are superimposed a number of extraordinary physiological and biochemical adaptations. Among the latter, the marked minima in respiratory metabolism and biosynthesis are especially prominent. When diapause is terminated in response to ecdysone 
(WILliams, 1947, 1952), a number of metabolic alterations are correlated with the resumption of generalized progress in development. In the face of this multiplicity of biochemical events, a major problem in discerning the biochemical action of ecdysone is that of distinguishing which of the various alterations are associated with development per se, and of these, which are primary from the standpoint of endocrine action.

The phenomenon of injury metabolism has already proven to be of some utility (see Shappirio, 1960) and continues to be of interest in this connexion. As we have seen, the changes in respiratory rate and oxidative enzyme activity which one observes after injury rather closely mimic those encountered when diapause is terminated in response to ecdysone. Similarly, the overall changes in nucleic acid and protein synthesis in many respects closely resemble those occurring when diapause is terminated. Yet the injured Cecropia pupa fails to exhibit any generalized development or other substantial morphogenetic response save for healing of the epidermal wound. One must conclude that these changes are, in themselves, insufficient for development and that they do not represent the immediate target of ecdysone. It seems certain that there is some critical difference between the response to injury and that to ecdysone.

The conclusion is then inescapable that a fruitful experimental approach to the mechanism of action of ecdysone lies not only in the comparison of the normal diapausing pupa with the developing adult, but also in the detailed comparison of the injured pupa with the developing adult. One seeks to identify biochemical or biophysical events which occur at an early stage in the termination of diapause, but not in the injured pupa. Such events may well form part of the critical sequence or network of processes that ecdysone promotes in its primary action upon the dormant tissues of the pupa. This approach has just recently been employed with success by BowERS and WrLIAMs (1964), whose findings point to deoxyribonucleic acid synthesis as a distinctive feature of the response to ecdysone in certain key target tissues.

Note added in proof-A similar conclusion regarding the close dependence of DNA synthesis upon ecdysone has also been reached by KrISHNAKumaran and ScHNEIDERMaN (F. Cell Biol. 23, 51A, 1964).

\section{REFERENCES}

BoNNEn W. D. Jr. (1964) Interactions between electron transport and the reactions of plant mitochondria with oxygen. Plant Physiol. (Suppl.) 39, lx (Abstract).

Bowers B. and Williams C. M. (1964) Physiology of insect diapause. XIII. DNA synthesis during the metamorphosis of the Cecropia silkworm. Biol. Bull, Woods Hole 126, 205-219.

Carey F. G. and Wyatt G. R. (1963) Phosphate compounds in tissues of the Cecropia silkmoth during diapause and development. F. Ins. Physiol. 9, 317-335.

Chance B. and HacketT D. P. (1959) The electron transfer system of skunk cabbage mitochondria. Plant Physiol. 34, 33-49.

Chance B. and Willaams G. R. (1956) The respiratory chain and oxidative phosphorylation. Advanc. Enzymol. 17, 65-134. 
De Duve C. and Berthet J. (1954) The use of differential centrifugation in the study of tissue enzymes. Int. Rev. Cytol. 3, 225-275.

DraBkin D. L. (1955) Independent biosynthesis of different haemin chromoproteins, with special reference to cytochrome $c$; the rôle of tissue organs. In Ciba Foundation Symposium on Porphyrin Biosynthesis and Metabolism (Ed. by WolstENHOLME G. E. W. and Millar E. C. P.). Little, Brown and Co., Boston.

Ephrussi B. and Beadle G. W. (1936) A technique of transplantation for Drosophila. Amer. Nat. 70, 218-225.

Fawcett C. P., Ciotti M. M., and Kaplan N. O. (1961) Inhibition of dehydrogenase rcactions by a substance formed from reduced diphosphopyridinc nuclcotide. Biochim. biophys. Acta 54, 210-212.

HARVEY W. R. (1956) The effect of carbon monoxide and diphtheria toxin on the injury metabolism of diapausing Cecropia silkworms. Anat. Rec. 125, 556 (Abstract).

HARVEY W. R. (1961) The respiratory exchange of diapausing pupae of the Cecropia silkworm in the presence of carbon ${ }^{14}$ monoxide. Biol. Bull., Woods Hole 120, 11-28.

Harvey W. R. (1962) Metabolic aspects of insect diapause. Annu. Rev. Ent. 7, 57-80.

HaRveY W. R. and Williams C. M. (1958a) Physiology of insect diapause. XI. Cyanidesensitivity of the heartbeat of the Cecropia silkworm, with special reference to the anaerobic capacity of the heart. Biol. Bull., Woods Hole 114, 23-35.

Harvey W. R. and Williams C. M. (1958b) Physiology of insect diapause. XII. The mechanism of carbon monoxide-sensitivity and -insensitivity during the pupal diapause of the Cecropia silkworm. Biol. Bull., Woods Hole 114, 36-53.

HaRveY W. R. and Williams C. M. (1961) The injury metabolism of the Cecropia silkworm-I. Biological amplification of the effects of localized injury. F. Ins. Physiol. 7, 81-99.

Hill R. and Hartree E. F. (1953) Hematin compounds in plants. Annu. Rev. Plant Physiol. 4, 115-150.

Iktuma H., Schindifr F. J., and BonNer W. D. Jr. (1964) Kinetic analysis of oxidases in tightly coupled plant mitochondria. Plant Physiol. (Suppl.) 39, 1x (Abstract).

KerLIN D. (1925) On cytochrome, a respiratory pigment, common to animals, yeast, and higher plants. Proc. roy. Soc. (B) 98, 312-339.

KIEIN O. and RunNström J. (1940) Considerations on the kinetics of respiration with special reference to the inhibition caused by carbon monoxide. Ark. Kemi Min. Geol. 14 A, 1-17.

KöHLER W. (1932) Die Entwicklung der Flügel bei der Mehlmotte Ephestia kühniella Zeller, mit besonderer Berücksichtigung des Zeichnungsmusters. Z. Morph. Ökol. Tiere 24, 582-681.

KreBs H. A. (1950) Body size and tissue respiration. Biochim. biophys. Acta 4, 249-269.

KrEBS H. A. (1959) Rate-limiting factors in cell respiration. In Ciba Foundation Symposium on the Regulation of Cell Metabolism (Ed. by Wolstenholme G. E. W. and O'Connor C. M.). J. and A. Churchill Ltd., London.

Kurland C. G. and Schneiderman H. A. (1959) The respiratory enzymes of diapausing silkworm pupae: A new interpretation of carbon monoxide-insensitive respiration. Biol. Bull., Woods Hole 116, 136-161.

MaRgoliash E. (1954) The use of ion exchangers in the preparation and purification of cytochrome $c$. Biochem. $\mathcal{F} .56,529-535$.

SanBorn R. C. and Williams C. M. (1950) The cytochrome system in the Cecropia silkworm, with special reference to the properties of a new component. F. gen. Physiol. 33, 579-588.

SchNeIDERMan H. A. and Williams C. M. (1953) The physiology of insect diapause. VII. The respiratory metabolism of the Cecropia silkworm during diapause and development. Biol. Bull., Woods Hole 105, 320-334. 
Schineiderman H. A. and Williams C. M. (1954) The physiology of insect diapause. VIII. Qualitative changes in the metabolism of the Cecropia silkworm during diapause and development. Biol. Bull., Woods Hole 106, 210-229.

Scholander P. F. (1947) Analyzer for accurate estimation of respiratory gases in onehalf cubic centimeter samples. F. biol. Chem. 167, 235-250.

Shappirio D. G. (1960) Oxidative enzymes and the injury metabolism of diapausing Cecropia silkworms. Ann. N.Y. Acad. Sci. 89, 537-548.

Shappirio D. G. and Williams C. M. (1957a) The cytochrome system of the Cecropia silkworm. I. Spectroscopic studies of individual tissues. Proc. roy. Soc. (B) 147, 218232.

Shappirio D. G. and Williams C. M. (1957b) The cytochrome system of the Cecropia silkworm. II. Spectrophotometric studies of oxidative enzyme systems in the wing cpithclium. Proc. roy. Soc. (B) 147, 233-246.

Siegel S. (1956) Nonparametric Statistics. McGraw-Hill Book Co., New York, Toronto, and London.

SirinNer D. M. (1963) Incorporation of labelled valine into the proteins of the Cecropia silkworm. Biol. Bull., Woods Hole 125, 165-176.

Stevenson E. and WyatT G. R. (1962) The metabolism of silkmoth tissues. 1. Incorporation of leucine into protein. Arch. Biochem. Biophys. 99, 65-71.

Telfer W. H. and Williams C. M. (1960) The effects of diapause, development and injury on the incorporation of radioactive glycine into the blood proteins of the Cecropia silkworm. F. Ins. Physiol. 5, 61-72.

Warburg O. (1927) Über die Wirkung von Kohlenoxyd und Stickoxyd auf Atmung und Gärung. Biochem. Z. 189, 354-380.

Williams C. M. (1946) Physiology of insect diapause: The role of the brain in the production and termination of pupal dormancy in the giant silkworm Platysamia cecropia. Biol. Bull., Woods Hole 90, 234-243.

Williams C. M. (1947) Physiology of insect diapause. II. Interaction between the pupal brain and prothoracic glands in the metamorphosis of the giant silkworm Platysamia cecropia. Biol. Bull., Woods Hole 93, 89-98.

Witrtams C. M. (1948) Extrinsic control of morphogenesis as illustrated in the metamorphosis of insects. Growth 12, 61-74.

Willians C. M. (1952) Physiology of insect diapause. IV. The brain and prothoracic glands as an endocrine system in the Cecropia silkworm. Biol. Bull., Woods Hole 103, 120-138.

Williams C. M. (1956) Physiology of insect diapause. X. An endocrine mechanism for the influence of temperature on the diapausing pupa of the Cecropia silkworm. Biol. Bull., Woods Hole 110, 201-218.

WOLSKY A. (1949) The effect of carbon monoxide on the respiration of artificially bivoltinized silkworm eggs. Curr. Sci. 18, 323-325.

WOLSKY A. (1959) Changes at fertilization: $\mathrm{O}_{2}$ consumption and resistance to poisons of the respiratory enzyme system. In Physiology of Insect Development (Ed. by CAMPBELL F. L.). The Developmental Biology Conference Series, 1956. The University of Chicago Press, Chicago.

WyatT G. R. (1963a) Biochemistry of diapause, development, and injury in silkworm pupae. In Insect Physiology, Proceedings of the 23rd Biology Colloquium, Oregon State University (Ed. by Brookes V. J.). Oregon State University Press.

WצAтT G. R. (1963b) Metabolic regulation in the development of insects. In Control Mechanisms in Respiration and Fermentation (Ed. by WRIGHT B.). The Ronald Press Co., New York.

Yocum C. S. and HackeTt D. P. (1957) Participation of cytochromes in the respiration of the Aroid spadix. Plant Physiol. 32, 186-191. 